\title{
Trabalho e sofrimento: a extinção de cargos na universidade pública
}

\author{
Work and suffering: the endangerment of positions at the public university
}

Trabajo y sufrimiento: la extinción de cargos en la universidad pública

THAIS FERRUGEM SARMENTO*

JUSSARA MARIA ROSA MENDES**

\begin{abstract}
$\longrightarrow \nLeftarrow$
RESUMO

Este artigo analisa os efeitos das transformações estruturais ocorridas nas universidades públicas federais e suas repercussões na saúde e no trabalho dos servidores ocupantes de cargos em extinção em uma universidade federal do sul do país. Para empreender esta análise, deu-se ênfase à abordagem qualitativa, à revisão do estado da arte sobre o tema e à realização de entrevistas semiestruturadas com a gestão superior da universidade, com a representação sindical e com nove servidores ativos ocupantes de cargos em processo de extinção. Os resultados evidenciam que as trajetórias desses servidores estão marcadas pelo sofrimento, pela discriminação e pela falta de alternativas para inserção no mercado de trabalho. As estratégias por eles empregadas para o enfrentamento das dificuldades em seu quotidiano de trabalho na universidade têm efeitos meramente paliativos, não sendo capazes de modificar a realidade em que se encontram. Tornam-se reféns e invisíveis, o que contribui para a produção do sofrimento e do adoecimento no trabalho.
\end{abstract}

Palavras-chave: Saúde. Trabalho. Universidade pública. Extinção de cargos. Sofrimento.

\begin{abstract}
This article analyzes the effects of structural changes in public federal universities and their impact on the health and work of public servants holding endangered positions at a federal university in Southern Brazil. As a means to undertake this analysis, emphasis was laid on the qualitative approach, on the review of the state of the art on the subject, and on conducting semi-structured interviews with nine of the aforementioned servants, as well as with one union representative and the university's management. The results highlight that the professional careers of these servants are marked by suffering, discrimination and lack of alternatives for labor market insertion. The strategies they use to cope with the difficulties in their daily work at the university have merely palliative effects and are not capable of modifying the reality in which they find themselves. Therefore, they become hostages and are invisible, which contributes to further suffering and diseases at work.
\end{abstract}

Keywords: Health. Work. Public university. Endangered positions. Suffering.

\section{RESUMEN}

Este estudio analiza los efectos de las transformaciones estructurales ocurridas en las universidades públicas federales y sus repercusiones en la salud y en el trabajo de los funcionarios de cargos extintos en una universidad federal del sur de Brasil. Para hacer este análisis, se realizó una investigación cualitativa por intermedio de una revisión de la literatura acerca de la temática y de entrevistas con una representante de la gestión de la universidad, una representante del sindicato y nueve funcionarios de los cargos en cuestión. Los resultados del estudio demuestran que las trayectorias de estos funcionarios se encuentran marcadas por el sufrimiento, por la discriminación y por la falta de alternativas para la inserción en el mercado de trabajo. Las estrategias utilizadas por estos funcionarios para enfrentar las dificultades en el trabajo solamente tienen efectos paliativos, pues no son capaces de cambiar la realidad que ellos viven en la universidad. Ellos se quedan rehenes e invisibles, hecho que contribuye con la producción del sufrimiento y de la enfermedad en el trabajo.

Palabras clave: Salud. Trabajo. Universidad pública. Extinción de cargos. Sufrimiento.

\footnotetext{
*Psicóloga, Especialista em Avaliação Psicológica e Mestre em Psicologia Social e Institucional pela UFRGS. E-mail: thaisfsarmento@gmail.com

**Assistente Social, mestre (PUCRS) e doutora em Serviço Social (PUC/SP). Docente dos cursos de graduação em Serviço Social e de pós-graduação em Psicologia Social e Institucional na UFRGS. Docente e coordenadora do curso de pós-graduação em Política Social e Serviço Social na UFRGS. E-mail: jussaramaria.mendes@gmail.com
} 


\section{INTRODUÇÃO}

A globalização da economia capitalista marcou e modificou profundamente as características internas na esfera econômica, social e cultural (FRIGOTTO, 2006; PAULANI, 2006). Dentre estas, ressalta-se a estratégia de extinção de cargos, adotada na reestruturação institucional no âmbito das universidades públicas.

Essa extinção é uma das propostas previstas na Reforma do Estado implementada nos anos 1990, em um cenário de crise econômica mundial (BRASIL, 1995). Com a intensificação dos processos de globalização e de mundialização do capital, a partir da década de 1980 (ALVES, 2001), houve redução da autonomia política e econômica dos países periféricos e semiperiféricos, como é o caso do Brasil (SANTOS, 2002, 2006). A extensa crise econômica ocorrida nas décadas de 1980 e 1990 atingiu intensamente os países da América do Sul, os quais sofriam as pressões de agências multilaterais, como o Fundo Monetário Internacional (FMI) e o Banco Mundial, para ajuste de suas economias e para o enfraquecimento do Estado segundo uma óptica neoliberal (LIMA; LEHER, 2014). No Brasil, a Reforma do Estado, ocorrida no primeiro período do governo Fernando Henrique Cardoso, consoante às orientações do Consenso de Washington e de agências multilaterais, levou a um amplo processo de reconfiguração da estrutura estatal e das políticas sociais (CHAUÍ, 2001; BRASIL, 1995).

O setor público passou a ser tratado como problema fiscal, impulsionando a redução de gastos com o funcionalismo público como medida necessária à retomada do crescimento econômico do país. Com isso, ocorreram a precarização das condições de trabalho, o congelamento de salários e o crescimento na contratação de trabalhadores temporários ou terceirizados (GOMES; SILVA; SÓRIA, 2012). A extinção de cargos, principalmente os de menor escolaridade, é justificada no Plano Diretor da Reforma do Estado com o seguinte argumento: a remuneração desses servidores é superior à praticada na iniciativa privada para trabalhadores com funções equivalentes (BRASIL, 1995). Ainda nos anos 1990, a Lei n. 9.632, de maio de 1998, implementou a extinção de cargos preconizada no Plano Diretor, deixando 72.930 servidores ativos na condição de ocupantes de cargos em processo de extinção e atingindo o conjunto do funcionalismo público federal, incluindo-se as instituições de ensino superior (BRASIL, 1998).

No caso das universidades, a extinção de cargos permanece ainda nos dias de hoje como um importante ponto de conflito entre as representações dos servidores e do governo. Por um lado, os representantes dos servidores argumentam que muitos dos cargos extintos abarcam atividades de caráter permanente e fundamentais para o adequado funcionamento institucional. Nessa linha, propõe-se a extinção apenas daqueles cargos cujas funções são transitórias ou foram incorporadas pelas mudanças nos processos de trabalho e defende-se a criação de novos cargos que contemplem aquelas atividades de caráter permanente constantes nas atribuições dos cargos extintos ou em processo de extinção. Por outro lado, representações do governo sustentam a manutenção da extinção, justificando que a contratação de serviços terceirizados é menos onerosa ao Estado (SARMENTO, 2016). A terceirização no serviço público, em substituição ao trabalho realizado por servidores cujos cargos estão em extinção no atual plano de carreira, além de não ser garantia de economia nos gastos, usualmente configura-se como uma forma de precarização do trabalho (ROSA, 2015).

É nesse contexto que se buscou analisar a problemática das mudanças estruturais ocorridas nas universidades públicas brasileiras e as implicações desse processo na saúde, no adoecimento e no sofrimento do e no trabalho desses servidores, marginalizados pelo processo de extinção de cargos.

\section{Metodologia}

Esta pesquisa enfoca as transformações ocorridas na universidade pública e seus efeitos sobre a saúde e sobre o trabalho de servidores que ocupam cargos em extinção. Desenvolveu-se em uma universidade federal do sul do país, a qual é composta por 5.504 servidores ativos, dos quais 2.697 são docentes e 2.707 são técnicoadministrativos em educação (TAEs). Entre os TAEs, cerca de 20\% (529 servidores) ocupam cargos em processo de extinção.

A coleta de dados ocorreu no período de julho/2015 a janeiro/2016, por meio de entrevistas semiestruturadas, as quais posteriormente foram submetidas à análise de conteúdo temática (BARDIN, 1977). Participaram nove servidores ativos, selecionados de forma aleatória, os quais ocupam os seguintes cargos em extinção: servente de limpeza, carpinteiro, porteiro, almoxarife, operador de máquina fotocopiadora, contínuo e vigilante. Participaram ainda uma servidora indicada pela gestão superior da universidade, a qual é ocupante de cargo de nível superior e trabalha na universidade há menos de dez anos, e uma servidora que participa do movimento sindical em diferentes entidades, há quase três décadas, e à época da entrevista integrava a coordenação do sindicato que representa os servidores da universidade. $\mathrm{Na}$ análise, busca-se discutir as relações entre saúde e trabalho na universidade, demonstrando o sofrimento vivenciado pelos servidores como um dos efeitos da extinção de cargos.

A pesquisa atendeu a todos os princípios da ética em estudos com seres humanos e obteve parecer favorável e consubstanciado do Comitê de Ética em Pesquisa via 
Plataforma Brasil; e a universidade emitiu manifestação formal de ciência e aceite para a sua realização. Os nomes dos participantes são fictícios e designados pelos sujeitos do estudo, indicando como gostariam de ser identificados. Eles consentiram em assinar o Termo de Consentimento Livre e Esclarecido.

\section{TRANSFORMAÇÕES E ESTRATÉGIAS DE GESTÃO EM UMA UNIVERSIDADE PÚBLICA}

A totalidade do material analisado permitiu classificar as seguintes categorias do estudo: (1) mercado de trabalho; (2) condições de trabalho; (3) características do cargo e das atividades desempenhadas. Na categoria mercado de trabalho foram agrupados relatos acerca das transformações do mundo do trabalho. Esses depoimentos não deixam dúvidas de que suas trajetórias são uma via crucis, marcada pela dificuldade de inserção no trabalho e pelo sofrimento. Todos os servidores apontam o desemprego, a dificuldade de reinserção no mercado de trabalho após períodos de afastamento e os baixos salários na iniciativa privada como justificativa para ingresso e permanência na universidade.

O Quadro 1 apresenta informações referentes ao cargo, ano de ingresso, nível de classificação, requisitos de ingresso e escolaridade atual do participante. Conforme pode ser observado, os servidores entrevistados no estudo ingressaram na universidade, entre as décadas de $1980 \mathrm{e}$ 1990. No Brasil, a reestruturação produtiva iniciada nos anos 1980 e intensificada nos anos 1990 foi acompanhada de uma série de políticas de cunho liberalizante, culminando num amplo processo de desestruturação do mercado de trabalho. Ocorreu o crescimento do desemprego e da inserção no mercado de trabalho de forma precarizada e informal, a redução dos níveis de remuneração, a intensificação do processo de terceirização e a ampliação dos mecanismos de desregulamentação do trabalho (ALVES, 2002; ANTUNES, 2003; CARDOSO JR., 2001; COSTA, 2005; MACIEL, 2006).

A exemplo disso, Cristiane menciona que, apesar de ser uma profissional experiente e qualificada em sua área, teve grandes dificuldades para encontrar emprego após ter-se afastado do trabalho por alguns anos para cuidar do filho e da família. Embora a vaga de servente de limpeza tivesse como requisito de ingresso apenas alfabetização, escolaridade inferior a que detinha na época como técnica em contabilidade, e abarcasse atividades distintas daquelas realizadas por ela, até então, o ingresso nessa função foi percebido como uma boa oportunidade de emprego. Para Negão, que anteriormente era alfaiate na área de alta costura, o ingresso na universidade, no início dos anos 1980, foi uma alternativa diante da necessidade de sustentar a família e da escassez de trabalho em sua área. Segundo ele, com a intensificação da produção de roupas industrializadas e com a crise econômica que se seguiu, seus clientes tornaram-se cada vez mais escassos. Giovani conta que o salário previsto para o cargo de operador de máquina fotocopiadora, na época de seu ingresso, era cerca de dez vezes superior ao que recebia para a mesma função na iniciativa privada. Segundo Giovani:

Quadro 1. Servidores ocupantes de cargos em extinção segundo ano de ingresso, cargo e nível de classificação, requisitos para o cargo e escolaridade

\begin{tabular}{|c|c|c|c|c|}
\hline $\begin{array}{l}\text { Nome do } \\
\text { servidor }\end{array}$ & $\begin{array}{l}\text { Ano de } \\
\text { ingresso }\end{array}$ & $\begin{array}{l}\text { Cargo e nível de } \\
\text { classificação }\end{array}$ & Requisitos para ingresso no cargo & $\begin{array}{l}\text { Escolaridade do } \\
\text { participante }\end{array}$ \\
\hline Cristiane & 1989 & Servente de limpeza (A) & Alfabetizado & $\begin{array}{l}\text { Curso técnico, } \\
\text { ensino superior incompleto }\end{array}$ \\
\hline Negão & 1981 & Carpinteiro (B) & $\begin{array}{l}\text { Ensino fundamental incompleto e experiência } \\
\text { de } 12 \text { meses ou profissionalizante }\end{array}$ & Ensino médio incompleto \\
\hline José & 1993 & Porteiro $(\mathrm{C})$ & Ensino médio completo & Pós-graduação \\
\hline Cláudio & 1992 & Almoxarife (C) & $\begin{array}{l}\text { Ensino médio completo e experiência de } \\
6 \text { meses }\end{array}$ & Pós-graduação \\
\hline Giovani & 1990 & $\begin{array}{l}\text { Operador de máquina } \\
\text { fotocopiadora }(\mathrm{C})\end{array}$ & $\begin{array}{l}\text { Ensino médio completo e experiência de } \\
12 \text { meses }\end{array}$ & Pós-graduação \\
\hline Solange & 1993 & Porteira $(\mathrm{C})$ & Ensino médio completo & $\begin{array}{l}\text { Ensino médio e } \\
\text { curso técnico }\end{array}$ \\
\hline Cristiano & 1993 & Contínuo (C) & $\begin{array}{l}\text { Ensino fundamental completo e experiência } \\
\text { de } 12 \text { meses }\end{array}$ & Pós-graduação \\
\hline Seu Silva & 1989 & Vigilante (D) & $\begin{array}{l}\text { Ensino fundamental completo, curso de } \\
\text { formação e } 12 \text { meses de experiência }\end{array}$ & Ensino médio incompleto \\
\hline Ricardo & 1990 & Vigilante (D) & $\begin{array}{l}\text { Ensino fundamental completo, curso de } \\
\text { formação e } 12 \text { meses de experiência }\end{array}$ & Ensino médio \\
\hline
\end{tabular}


Eu era fotocopista [em um banco público], na empresa terceirizada que prestava serviço [pro banco]. Então, assim, eu ingressei na universidade, um colega de aula que trabalhava aqui me informou do concurso, que era uma oportunidade de emprego, até porque eles não pagavam muito bem. Eu trabalhava seis horas e, na época, ganhava menos que o mínimo. [...] No começo foi por isso. Um salário melhor e segurança [...] porque o salário que eu ganharia [na universidade] era dez vezes mais do que eu tava ganhando lá fora.

O serviço público apresenta-se como uma oportunidade de proteção ao trabalhador que busca emprego estável (HOLZMANN, 2006). Mesmo quando o cargo ocupado se diferencia das experiências profissionais anteriores, como relatado por Negão e Cristiane, ou quando a escolaridade do servidor é superior à exigida pelo cargo, como é o caso de todos os entrevistados, tema esse aprofundado posteriormente. Em geral, os servidores descrevem a busca de emprego na iniciativa privada como altamente desvantajosa diante da estabilidade do serviço público. Assim, apesar de mencionarem diferentes formas de sofrimento no trabalho, eles descrevem a permanência na universidade como a alternativa menos danosa diante de suas limitadas possibilidades de reinserção no mercado de trabalho.

As condições de trabalho incluem as normas institucionais, as características dos processos de gestão, da infraestrutura e da composição do quadro de trabalhadores da universidade. Entre as transformações nas condições de trabalho relatadas pelos servidores, destacam-se as modificações na forma de ingresso na universidade, a extinção de cargos e a terceirização. Os servidores referem diferentes modalidades de ingresso, conforme mudanças na legislação vigente. Ao contrário dos demais participantes, os quais ingressaram na universidade após aprovação em concurso público, Cristiane e Negão foram contratados em regime de CLT, a partir da indicação de familiares e conhecidos vinculados à universidade. Até o final dos anos 1980, o ingresso no serviço público não estava condicionado à aprovação prévia em concurso, sendo comum a contratação direta de trabalhadores em regime de CLT. A partir dos anos 1990, todos os servidores foram reenquadrados e passaram a ter seu vínculo regulamentado pelo regime estatutário (ROSA, 2015).

Simone, representante sindical entrevistada, destaca a extinção de cargos como uma importante mudança na carreira dos servidores ocorrida na década de 1990. Segundo ela, aquela foi uma época de acentuada perda salarial, retirada de direitos dos servidores, redução da estrutura estatal e sucateamento do serviço público e das universidades. Foi um período de severa precarização da universidade, no qual houve uma drástica redução de verbas destinadas à manutenção de sua infraestrutura, e ocorreu o congelamento dos salários, chegando a seu patamar mais baixo no início dos anos 2000. A ausência de concursos contribuiu para o envelhecimento e para a redução do quadro de servidores devido à falta de reposição, criando uma grande sobrecarga de trabalho (LIMA; PEREIRA, 2009; BOSI, 2007; LUCAS; LEHER, 2001).

Diante da lacuna de servidores em algumas áreas, os entrevistados buscam atender às demandas de trabalho, utilizando-se predominantemente de estratégias individuais, como a intensificação dos ritmos de trabalho e a extensão da jornada. A principal estratégia coletiva relatada pelos servidores para lidar com as dificuldades enfrentadas refere-se à construção de laços de suporte e ajuda mútua, sendo a manutenção de boas relações entre colegas ponto fundamental para tornar o trabalho possível. Para Seu Silva e Ricardo, parte considerável do trabalho realizado como vigilantes consiste em manejar situações de desrespeito às normas e de conflito entre diferentes membros da universidade. Segundo eles, para que isso seja feito de forma satisfatória, é indispensável o estabelecimento de relações de parceria. Negão descreve a prática de trocas e empréstimos entre os setores como uma forma de contornar a falta de materiais.

A progressiva intensificação das cobranças feitas pela gestão nos últimos anos, concomitantemente à precariedade das condições de trabalho - seja pela falta de pessoal, seja pela carência de materiais adequados -, é descrita pelos servidores e por Simone como importante fonte de sofrimento no trabalho. A esse respeito, Negão relata:

A administração geral é um pouco ditadura, sabe? [...] Eles só querem que faça as coisas urgente. Alguém cobra deles, eles querem que faça urgente. Às vezes, tu não tem como fazer e eles ficam cobrando. "Bah, a ponte ali vai cair. Vocês têm que fazer!". "Tá, mas não tem pessoal!". "Não, mas tem que dar um jeito!”. [...] E a gente consegue, assim, ó, é dar nó em pingo d'água. Por causa que a coisa é bem complicada.

Para Simone, diferentemente do que ocorria em décadas anteriores, atualmente são muito comuns entre os servidores queixas relacionadas ao sofrimento no trabalho, o que converge com os achados de diferentes estudos. O crescimento das demandas de trabalho, a intensificação do individualismo e das cobranças sobre os servidores, acompanhadas de condições de trabalho insuficientes são alguns dos fatores que contribuem para o elevado número de queixas relacionadas ao sofrimento e ao esvaziamento do sentido do trabalho (SAMPAIO et al., 2003; COSTA et al., 2005; JUNIOR, 2010; CARAN et al., 2011; BRITES; ABREU; PINTO, 2014). A exemplo 
disso, Simone relata situações semelhantes àquelas descritas pelos participantes deste estudo. Menciona o caso de uma servidora que atua em setor que acolhe as demandas de outros servidores, ofertando um tipo de atendimento que requer sigilo e privacidade. A falta de salas adequadas para realizar suas atividades muitas vezes faz com que ela permaneça parte de sua jornada impossibilitada de realizar sua principal atribuição, que é $o$ atendimento aos servidores. Configura-se, assim, uma situação na qual a trabalhadora se vê impedida de realizar o trabalho que lhe é demandado.

Além da falta de infraestrutura e de materiais, os entrevistados abordam também a acentuada redução do quadro geral de servidores nos anos 1990, a qual foi acompanhada de uma intensificação das terceirizações na universidade. Estas tiveram início nas décadas de 1970 e 1980, atendendo às crescentes demandas dos campi, e intensificaram-se novamente nos anos 1990, suprindo parcialmente a falta de pessoal decorrente das aposentadorias e da falta de concursos (ROSA, 2015).

Características do cargo e das atividades desempenhadas referem-se às atribuições prescritas pela descrição do cargo e às atividades reais executadas pelo servidor, as quais comumente não correspondem àquelas previstas nas especificações do cargo. Excetuando-se os vigilantes, os quais sempre permaneceram realizando atividades semelhantes, todos os demais servidores entrevistados descrevem modificações nas funções por eles desempenhadas, ao longo dos anos de serviço, afastando-se em diferentes medidas das prescrições do cargo ocupado. Relatam ter desenvolvido diferentes capacidades profissionais através de cursos de formação e da experiência de trabalho dentro e fora da universidade, tornando-se aptos a realizar atividades diferentes daquelas previstas em seus cargos. Destaque-se que atualmente todos os entrevistados apresentam escolaridade superior à exigida pelo cargo, sendo que alguns já ingressaram nessa condição, ao passo que outros a alcançaram ao longo dos anos de serviço.

José, porteiro da universidade que chegou a cursar pós-graduação, aborda o sofrimento atrelado à falta de reconhecimento do trabalho e das capacidades desses servidores:

Muitas vezes, eu sofri preconceito porque eu sou porteiro [...]. Talvez não exista mais essa valorização do cargo porque é um cargo em extinção. [...] Hoje em dia, eu não vejo mais perspectivas. Assim, infelizmente, to bem desmotivado com relação a isso. Espero que outros colegas... Só que aí eu não tenho a força dos colegas novos. Diferente dos outros cargos "não em extinção", que as pessoas quando elas entram elas querem melhorar. [...] Talvez por ser um cargo em extinção não haja necessidade de a gente lutar pela causa dos porteiros, por exemplo. [...] Muitas vezes, eu vim trabalhar desmotivado.
Em seu relato, ele afirma que a redução no número de servidores nesses cargos contribui para que aqueles que permanecem na universidade se tornem invisíveis e para que suas possibilidades de enfrentamento coletivo das dificuldades sejam cada vez mais limitadas. Diante do sofrimento relacionado à condição de invisibilidade, à falta de reconhecimento e às restritas possibilidades de articulação coletiva entre esses servidores, José recorre à psicoterapia individual como alternativa para lidar com as limitações de sua realidade de trabalho. A busca individual de meios para atenuar o sofrimento no trabalho, recurso que usualmente não é capaz de modificar as situações vividas pelo trabalhador, é uma estratégia comum entre os servidores das universidades (COSTA et al., 2005; BERNARDO, 2014).

No que se refere às suas atividades, alguns servidores mencionam uma relação íntima entre a modificação de suas atribuições e a terceirização. $\mathrm{O}$ aumento no número de trabalhadores terceirizados em funções de apoio, como limpeza e portaria, permitiu que os servidores que executavam essas mesmas atividades fossem deslocados para outras funções, então carentes de profissionais. $\mathrm{Ou}$ seja, a ampliação da contratação de empresa terceirizada para exercer as mesmas funções dos servidores ocupantes de cargos em extinção cria condições favoráveis para que estes últimos afastem-se de suas atribuições originais e desenvolvam outras atividades. Segundo Juliana, representante do setor de gestão da universidade, o desvio de função é uma das principais características dos cargos em extinção. Embora comum, o desvio de função é uma prática irregular que deve ser evitada ou corrigida através da indicação de que o servidor retorne a sua função original.

E aí eu exerci, eu acho que por um ano e meio, dois, a função de servente de limpeza. Aí até que entrou a terceirização. [...] Aí o diretor me perguntou o que eu fazia antes, aí ele veio conversar comigo. Eu disse que trabalhava num escritório de contabilidade, que trabalhei dois anos num escritório de contabilidade. Perguntou minha formação. Eu disse que eu tinha o segundo grau completo, na época datilografia, né (risos), tinha algum conhecimento, assim, de documentação, de trâmite administrativo. Aí ele disse assim: "Então tá, como tá entrando essa empresa, então tu vai começar a fazer uma outra função". Aí eu comecei fazendo portaria... aliás, cafezinho! [...] E aí sentiram a necessidade de ter mais alguém na portaria, né, aí me perguntaram se eu aceitava entregar chaves. [...] Aí, um tempo depois, veio o xerox, que a gente tinha uma máquina de Xerox aqui, né. Era uma máquina locada pela [universidade]. Então eu entregava a chave e fazia xerox. [...] Aí, em 96 [...] tivemos várias reuniões, várias conversas, né, que ia modificar também o trabalho, né, e a turma ia se dividir [...] E aí no caso a contabilidade, [a servidora] que 
fazia, e ela foi [pra outra unidade]. E aí ficou aberto o setor de... o setor financeiro, quem faria os empenhos. Aí me perguntaram se eu poderia fazer os empenhos. [...] Agora, eu to como gerente administrativa [da unidade] (Cristiane).

A trajetória de Cristiane, servente de limpeza, exemplifica as modificações nas atividades realizadas pelos servidores. Segundo relato acima, ela descreve a forma pela qual a junção entre suas capacidades, a falta de servidores e a terceirização a levaram a distanciar-se dos fazeres típicos do servente de limpeza até tornar-se gerente administrativa de seu setor. Conforme sua descrição, quando a limpeza da universidade passou a ser feita pela empresa terceirizada, criaram-se as condições para que ela se dedicasse a diferentes atividades, atendendo às necessidades emergentes do setor.

Diferentemente de Cristiane, que afirma nunca ter refletido sobre as mudanças em suas funções, Solange descreve esse processo como fonte de conflito e sofrimento no trabalho. Segundo ela, o pedido para realizar novas tarefas resulta, em parte, da confiança depositada em sua experiência e capacidade profissional. Ao mesmo tempo, ressente-se por não poder formalizar a mudança de cargo e receber salário compatível com suas atividades. Para ela, os servidores ocupantes de cargos em extinção são um "quebra-galho", e graças ao amplo conhecimento institucional proporcionado pelos anos de serviço tornam-se aptos a suprir as diferentes lacunas da universidade. Cristiano acrescenta que as mudanças em suas atividades o levaram a viver em uma condição de clandestinidade, pois o desvio de função é uma prática irregular. Por conseguinte, angustia-se ao fazer quaisquer solicitações administrativas que lhe exijam descrever suas atividades - como pedidos de progressão funcional, por exemplo -, pois esse procedimento invariavelmente resulta na orientação formal de que retorne às atividades do cargo de contínuo as quais nunca chegou a exercer de fato.

\section{IMBRICAÇÕES ENTRE SAÚDE E TRABALHO NA UNIVERSIDADE PÚBLICA: SERVIDORES OCUPANTES DE CARGOS EM EXTINÇÃO}

A economia brasileira passava por um período de intensa instabilidade nos anos 1980 e 1990, época em que os servidores entrevistados ingressaram na universidade. Em 1980, o país enfrentava a diminuição do produto interno bruto, o crescimento das taxas de inflação e o aumento do endividamento do Estado (MACIEL, 2006; CARDOSO, 2001). Iniciava-se um processo de reestruturação produtiva, intensificada em 1990, além da redução dos postos de trabalho, crescimento do desemprego e do trabalho informal. Precário ou a domicílio, diminuição dos níveis de remuneração e crescimento da desregulamentação do trabalho. O que resultou na retirada de direitos e na intensificação da insegurança no trabalho (ALVES, 2002, 2007; ANTUNES, 2003, 2012; ANTUNES; POCHMANN, 2008; COSTA, 2005; MACIEL, 2006; ROSA, 2015). É em meio a essa realidade que a busca pelo ingresso na universidade foi descrita pelos servidores como alternativa ao desemprego, à instabilidade e aos baixos salários.

Em decorrência de uma cidadania regulada, no seio da qual o direito à seguridade está atrelado à contribuição e ao contrato formal de trabalho, e da fragilidade dos mecanismos de proteção social, o acesso ao emprego torna-se condição fundamental para a manutenção da existência (COSTA, 2005; NARDI, 2006). Ademais, a inserção no trabalho é um importante mecanismo de pertencimento social (CASTEL, 2008a, 2008b, 2013) e contribui para a construção da identidade e das interações sociais, sendo uma relevante fonte de valorização do sujeito. O temor do desemprego, portanto, está associado à preocupação com a manutenção das condições de vida, com a desvalorização social do desempregado e com o sofrimento atrelado a essa condição (LINHART, 2007; SELIGMANN-SILVA, 2011).

A inserção na universidade é descrita pelos participantes do estudo, ao mesmo tempo, como fonte de proteção e de sofrimento. Apesar das dificuldades relatadas pelos servidores, sua permanência nos cargos ocupados, ainda hoje, é percebida como a condição menos danosa diante das limitadas alternativas de acesso ao mercado de trabalho. A progressiva desregulamentação e desestruturação do trabalho na realidade brasileira têm efeitos mais acentuados em alguns grupos, criando maiores dificuldades de inserção no mercado para trabalhadores com mais de 40 anos (ANTUNES, 2009), como é o caso dos servidores entrevistados. Adicionalmente, as características do regime jurídico que rege o vínculo atual dos participantes com a universidade e do atual plano de carreira dos TAEs tornam ainda mais acentuadas as desvantagens da busca por emprego na iniciativa privada e mesmo de um novo ingresso no serviço público. Além das especificidades do regime jurídico, que permite aos servidores considerável segurança quanto à permanência no serviço público, o plano de carreira vigente possibilita um aumento salarial progressivo decorrente das avaliações de desempenho e da participação em cursos de qualificação e capacitação. Dessa forma, servidores com escolaridade acima da exigida pelo cargo ocupado e com longos anos de serviço comumente alcançam uma remuneração superior àquela que receberiam caso reingressassem na universidade, nos dias de hoje, em cargo compatível com seu nível de formação. Ou seja, um 
novo ingresso em cargo condizente com sua qualificação, em muitas situações, resultaria em perdas salariais (SARMENTO, 2016).

Embora o Plano de Carreira dos Cargos TécnicoAdministrativos em Educação (PCCTAE) estabeleça em suas diretrizes a oferta de ações de capacitação e especifique normas para recebimento de adicionais remuneratórios conforme nível de formação do servidor, o rol de atividades desenvolvidas deve restringirse àquelas previstas em seu cargo (BRASIL, 2005). A progressão funcional no serviço público, devido à excessiva rigidez dos planos de carreira, usualmente resulta em aumento salarial sem possibilitar alteração ou aumento da complexidade das atividades realizadas pelo servidor (MARCONI, 2003). Em caráter não excepcional, a realização de atividades distintas daquelas previstas na descrição do cargo ocupado pode caracterizar desvio de função, prática vetada pela atual legislação. O que pode resultar em indenização ao servidor conforme a diferença salarial entre seu cargo e aquele correspondente às funções efetivamente exercidas (ANDRADE, 2012).

A precarização das condições de trabalho foi um fenômeno que atingiu intensamente o conjunto do funcionalismo público ao longo dos anos 1990. Pautando-se em orientações de cunho fortemente neoliberal, as políticas de governo adotadas naquele momento promoveram a drástica redução do aparelho do Estado e o sucateamento do serviço público. Foi um período marcado pelo corte de gastos, pelo achatamento salarial, pela postura autoritária do governo em relação às organizações sindicais, pela ampliação dos quadros de trabalhadores terceirizados ou temporários e pela ausência de concursos, levando à redução do quadro e ao aumento da idade média dos servidores. No caso das universidades, a redução no número de servidores foi tão acentuada que chegou a comprometer seu funcionamento (GOMES; SILVA; SÓRIA, 2012; MARCONI, 2003).

Nos anos 2000, o setor público era tratado de forma ambígua. De um lado, priorizava a criação de políticas de capacitação e de saúde do servidor, a retomada dos concursos públicos, a melhoria dos planos de carreira, dos salários, das condições e dos processos de trabalho. De outro, promovia a reforma da previdência, com retirada de direitos, interrompendo o incipiente diálogo com as representações sindicais (GOMES; SILVA; SÓRIA, 2012). A partir do governo Lula, as universidades públicas passaram por um intenso processo de ampliação, mediante aumento na oferta de vagas, criação de novos campi e ampliação dos já existentes. No entanto, ao longo dos governos Lula e Dilma, os acréscimos em infraestrutura e em recursos humanos foram desproporcionais ao crescimento no número de vagas, levando a um processo de expansão precarizado, o qual se sustentou à custa da intensificação do trabalho e do sofrimento dos servidores (LIMA, 2011; LIMA; LIMA-FILHO, 2009; BERNARDO, 2014). As recentes propostas que vêm sendo implementadas pelo governo Temer tendem a acentuar ainda mais a precarização das universidades e seus efeitos deletérios na saúde e no trabalho dos servidores. Ao longo de seu governo, vêm ocorrendo a retomada e o aprofundamento da agenda neoliberal dos anos 1990, o que se manifesta marcadamente pela ampla retirada de direitos sociais. Ocorre, entre outros, o congelamento dos gastos com educação e a extrema ampliação da desregulamentação do trabalho, tornando-o cada vez mais flexível e precário (MELO; SOUZA, 2017, SANTOS, 2016). Tal realidade contribui para o agravamento das dificuldades vividas pelos servidores nas universidades e para a redução das já limitadas alternativas desses trabalhadores.

\section{CONSIDERAÇõES FINAIS}

Os entrevistados descrevem diferentes situações que contribuem para a produção de sofrimento no trabalho na universidade. Tais queixas são associadas predominantemente à insuficiência das condições de trabalho, às lógicas institucionais que acentuam o individualismo e a culpabilização do trabalhador, à intensificação das cobranças e das exigências feitas pela gestão, confirmando estudos realizados e citados anteriormente (SAMPAIO et al., 2003; COSTA et al., 2005; JUNIOR, 2010; CARAN et al., 2011; BRITES; ABREU; PINTO, 2014). As narrativas dos participantes explicitam o desvio de função como uma estratégia institucional utilizada de forma recorrente para suprir as lacunas ocasionadas pela falta de trabalhadores em algumas áreas. A grande maleabilidade na designação de funções já faz parte da cultura institucional, situação alcançada através de relações de cumplicidade estabelecidas entre chefia e servidor, permitindo, dessa forma, atender às demandas emergentes e àquelas decorrentes da falta de pessoal qualificado. Portanto, evidencia-se um entrelaçamento entre a insuficiência das condições de trabalho e as metamorfoses das funções do servidor.

Acrescenta-se a esse contexto a invisibilidade que envolve a progressiva redução do número de servidores ocupantes desses cargos, a clandestinidade inerente ao desvio de função e as novas exigências postas às universidades. As práticas de gestão encontram-se marcadas pela intensificação das exigências feitas aos servidores - acompanhadas da falta de suporte e de condições adequadas ao trabalho - e pelo imperativo de vigilância e correção daquilo que fere os diferentes regramentos institucionais, como é o caso do desvio de função. As determinações legais vigentes e as práticas de 
gestão, que exigem a correção do desvio de função e o cumprimento das atribuições originais desses servidores, conforme previstas na descrição dos cargos ocupados por eles, contribuem para invisibilizar os processos sociais e institucionais que produzem a realidade de trabalho, o sofrimento e o adoecimento na universidade. Não obstante suas trajetórias de trabalho se constituam a partir de processos que extrapolam a esfera de suas escolhas individuais, o ônus dessa realidade recai sobre os servidores. A adoção, no serviço público, de ferramentas de gestão importadas da iniciativa privada, principalmente a partir dos anos 1990, contribui para a culpabilização e responsabilização dos servidores por suas condições de trabalho, para a intensificação do individualismo e para a fragilização das estratégias coletivas de resistência (NEVES, 2005; SPILKI; TITONI, 2005). A substituição de servidores por profissionais terceirizados contribui para a fragmentação da representação sindical, dificultando a resistência coletiva na luta por direitos e por melhores condições de trabalho. Histórias de vida profissional desses servidores ocupantes de cargos em extinção expõem os efeitos das transformações no mundo do trabalho, na universidade pública brasileira. Características como o desemprego, a inserção precária e mal remunerada, conjuntamente com a precarização, com o desmonte e com as mudanças na gestão e na organização da universidade pública, repercutem na saúde, nas sociabilidades e nos modos de viver e adoecer desses servidores. Condições de trabalho insuficientes, ausência de reconhecimento, dominação, discriminação, exploração, cobranças e culpabilização são alguns componentes que, sob o "manto da modernização" na gestão pública, refletem negativamente na saúde e na produção de sofrimento no trabalho desses servidores. Tratam-se de múltiplas correlações desiguais que marcam a coisificação da condição humana nesse espaço ocupacional, cuja sujeição do trabalhador o "torna expropriado de componentes relevantes de sua subjetividade" (SELIGMANN-SILVA, 2011). As estratégias utilizadas por esses servidores - sejam elas individuais ou coletivas - mostram-se demasiadamente frágeis para combater o ataque a sua dignidade ou para promover mudanças na realidade em que se encontram.

As metamorfoses no mundo do trabalho, articuladas à exploração e à dominação, mostram-se como componentes centrais da supressão de laços. Dilaceram as relações sociais do e no trabalho e a saúde desses servidores, marcadas pelo sofrimento social e degradação ética no trabalho.

\section{REFERÊNCIAS}

ALVES, G. Dimensões da globalização: o capital e suas contradições. Londrina: Praxis, 2001.
ALVES, G. Trabalho e sindicalismo no Brasil: um balanço crítico da "década neoliberal" (1990-2000). Revista de Sociologia e Política, v. 19, p. 71-94, 2002.

ALVES, G. Dimensões da reestruturação produtiva: ensaios de sociologia do trabalho. Londrina: Praxis, 2007.

ANDRADE, M. B. O desvio ilegal de função de servidor público titular de cargo efetivo como prática atentatória aos princípios da legalidade, da moralidade e da impessoalidade. Revista Espaço Acadêmico, n. 132, p. 79-87, 2012.

ANTUNES, R. Os caminhos da liofilização organizacional: as formas diferenciadas da reestruturação produtiva no Brasil. Ideias, v. 10, n. 1, p. 13-24, 2003.

ANTUNES, R. O trabalho, sua nova morfologia e a era da precarização estrutural. Revista Theomai, n. 19, p.47-57, 2009.

ANTUNES, R. A nova morfologia do trabalho no Brasil: reestruturação e precariedade. Nueva Sociedad Especial em Português, 2012. p. 44-59.

ANTUNES, R.; POCHMANN, M. Dimensões do desemprego e da pobreza no Brasil. InterfacEHS - Revista de Gestão Integrada em Saúde do Trabalho e Meio Ambiente, v. 3, n. 2, p. 2-10, 2008

ARAÚJO, T. M.; SENA, I. P.; VIANA, M. A.; ARAÚJO, E. M. Mal-estar docente: avaliação de condições de trabalho e saúde em uma instituição de ensino superior. Revista Baiana de Saúde Pública, v. 29, n. 1, p. 6-21, 2005.

BARDIN, L. Análise de conteúdo. Lisboa: Edições 70, 1977.

BERNARDO, M. H. Produtivismo e precariedade subjetiva na universidade pública: o desgaste mental dos docentes. Psicologia \& Sociedade, v. 26, n. esp., p. 129-139, 2014.

BOSI, A. P. A precarização do trabalho docente nas instituições de ensino superior do Brasil nesses últimos 25 anos. Educação e Sociedade, v. 28, n. 101, 1503-1523, 2007.

BRASIL. Câmara da Reforma do Estado. Plano diretor da reforma do aparelho do Estado. Brasília, 1995.

BRASIL. Congresso Nacional. Lei no 11.091, de 12 de janeiro de 2005. Dispõe sobre a estruturação do Plano de Carreira dos Cargos Técnico-Administrativos em Educação, no âmbito das Instituições Federais de Ensino Superior vinculadas ao Ministério da Educação, e dá outras providências. Brasília: 2005 .

BRASIL. Congresso Nacional. Lei no 9.632, de 7 de maio de 1998. Dispõe sobre a extinção de cargos no âmbito da administração pública federal direta, autárquica e fundacional, e dá outras providências. Brasília: 1998.

BRITES, R. M. R.; ABREU, A. M. M. Padrão de consumo de bebidas alcoólicas entre os trabalhadores e perfil socioeconômico. Acta Paulista de Enfermagem, v. 27, n. 2, p. 93-99, 2014.

BRITES, R. M. R.; ABREU, A. M. M.; PINTO, J. E. S. S. Prevalência de alcoolismo no perfil das aposentadorias por invalidez dentre trabalhadores de uma universidade federal. Revista Brasileira de Enfermagem, v. 67, n. 3, p. 373-380, 2014.

CARAN, V. C. S.; FREITAS, F. C. T.; ALVES, L. A.; PEDRÃO, L. J.; ROBAZZI, M. L. C. Riscos ocupacionais psicossociais e sua repercussão na saúde de docentes universitários. Revista Enfermagem Uerj, v. 19, n. 2, p. 255-261, 2011. 
CARDOSO JR., J. C. Crise e desregulação do trabalho no Brasil. Tempo Social, v. 13, n. 2, p. 31-59, 2001.

CASTEL, R. As armadilhas da exclusão. In: BELFIOREWANDERLEY, M.; BÓGUS, L.; YAZBEK, M. C. (Orgs.). Desigualdade e a questão social. São Paulo: Educ, 2008a. p. 21-54.

CASTEL, R. As transformações da questão social. In: BELFIORE-WANDERLEY, M.; BÓGUS, L.; YAZBEK, M. C. (Orgs.). Desigualdade e a questão social. São Paulo: EDUC, 2008b. p. 227-256.

CASTEL, R. As metamorfoses da questão social: uma crônica do salário. Petrópolis: Vozes, 2013.

CHAUÍ, M. Escritos sobre a universidade. São Paulo: Unifesp, 2001.

COSTA, E. C.; BACHION, M. M.; GODOY, L. F.; ABREU, L. O. Percepções sobre o estresse entre professores universitários. Revista Rene, v. 6, n. 3, p. 39-47, 2005.

COSTA, M. S. O sistema de relações de trabalho no Brasil: alguns traços históricos e sua precarização atual. Revista Brasileira de Ciências Sociais, v. 20, n. 59, p. 111-131, 2005.

FRIGOTTO, G. Fundamentos científicos e técnicos da relação trabalho e educação no Brasil de hoje. In: LIMA, J. C.; NEVES, L. M. W. Fundamentos da educação escolar no Brasil contemporâneo. Rio de Janeiro: Fiocruz/EPSJV, 2006. p. 241-260.

GOMES, D. C.; SILVA, L. B.; SÓRIA, S. Condições e relações de trabalho no serviço público: o caso do governo Lula. Revista de Sociologia e Política, v. 20, n. 42, p. 167-181, 2012.

GUIMARÃES, L. A. M.; MARTINS, D. A.; GRUBITS, S.; CAETANO, D. Prevalência de transtornos mentais em trabalhadores de uma universidade pública do estado de São Paulo. Revista Brasileira de Saúde Ocupacional, v. 31, n. 113, p. 07-18, 2006.

HOLZMANN, L. A. Tendências do trabalho precário no Brasil no início do século XXI. In: PICCININI, V.; HOLZMANN, L.; KIVACS, I.; GUIMARÃES, V. N. (Orgs.). O mosaico do trabalho na sociedade contemporânea: persistências e inovações. Porto Alegre: Editora da UFRGS, 2006. p. 71-92.

JUNIOR, O. G. Sofrimento psíquico e trabalho intelectual. Cadernos de Psicologia do Trabalho, v. 13, n. 1, p. 133-148, 2010.

LIMA, J. F.; RAIHER, A. P. Do neoliberalismo ao intervencionismo: apontamentos sobre a economia da América do Sul. In: SILVA, L. A. M., MANDALOZZO, S. S. N., MENDES, J. M. R. (Orgs.). Trabalho e Proteção Social. Ponta Grossa: Estúdio Texto, 2014. p. 173-186.

LIMA, K. R. S. O Banco Mundial e a educação superior brasileira na primeira década do novo século. Revista Katálysis, v. 14, n. 1, p. 86-94, 2011.

LIMA, M. F. E. M; LIMA-FILHO, D. O. Condições de trabalho e saúde do/a professor/a universitário/a. Ciências \& Cognição, v. 14, n. 3, p. 62-82, 2009.

LIMA, K. R. S.; PEREIRA, L. D. Contra-reforma da educação superior brasileira: impactos na formação profissional em Serviço Social. Sociedade em Debate, v. 15, n. 1, p. 31-50, 2009.

LINHART, D. A desmedida do capital. São Paulo: Boitempo, 2007.

LUCAS, L. C. G.; LEHER, R. Aonde vai a educação pública brasileira? Educação \& Sociedade, n. 77, p. 255-266, 2001.
MACIEL, A. L. S. Universidade em crise: uma travessia necessária para a formação em Serviço Social. 2006. $220 \mathrm{f}$. Tese (Doutorado em Serviço Social) - Pontifícia Universidade Católica do Rio Grande do Sul, Porto Alegre, 2006.

MARCONI, N. A evolução do perfil da força de trabalho e das remunerações nos setores público e privado ao longo da década de 1990. Revista do Serviço Público, v. 54, n. 1, p. 09-45, 2003.

MELO, A. A. S.; SOUSA, F. B. A agenda do mercado e a educação no governo Temer. Germinal: Marxismo e Educação em Debate, v. 9, n. 1, p. 25-36, 2017.

MIRANDA, L. C. S, PEREIRA, C. A., PASSOS, J. P. O estresse dos docentes de enfermagem de uma universidade pública. Revista de Pesquisa: Cuidado é Fundamental [Online], v. 1, n. 2, 2009.

MIRANZI, S. S. C.; GASPAR, A. A. C. S.; IWAMOTO, H. H.; MIRANZI, M. A. S.; DZIABAS, D. C. Acidentes de trabalho entre trabalhadores de uma universidade pública. Revista Brasileira de Saúde Ocupacional, v. 33, n. 118, p. 40-47, 2008.

NARDI, H. C. Ética, trabalho e subjetividade: trajetórias de vida no contexto das transformações do capitalismo contemporâneo. Porto Alegre: Editora da UFRGS, 2006.

NEVES, J. M. A face oculta da organização: a microfísica do poder na gestão do trabalho. Porto Alegre: Ed. UFRGS/Sulina, 2005.

PAULANI, L. M. O projeto neoliberal para a sociedade brasileira: sua dinâmica e seus impasses. In: LIMA, J. C.; NEVES, L. M. W. Fundamentos da educação escolar no Brasil contemporâneo. Rio de Janeiro: Fiocruz/EPSJV, 2006, p. 67-83.

ROSA, A. S. Histórias e trajetórias da terceirização na UFRGS. 2015. 95 f. Dissertação (Mestrado em Administração) - Universidade Federal do Rio Grande do Sul, Porto Alegre, 2015.

SANTOS, B. S. Os processos de globalização. In: SANTOS, B. S. (Org.). A globalização e as Ciências Sociais. São Paulo: Cortez: 2002.

SANTOS, B. S. Globalizations. Theory Culture Society, v. 23, 393-399, 2006.

SAMPAIO, R. F.; SILVEIRA, A. M.; PARREIRA, V. F.; MAKINO, A. T.; MATEO, M. M. Análise das aposentadorias por incapacidade permanente entre os trabalhadores da Universidade Federal de Minas Gerais no período de 1966 a 1999. Revista da Associação Médica Brasileira, v. 49, n. 1, p. 60-66, 2003.

SANTOS, R. A retomada do programa neoliberal no governo Temer e seus possíveis impactos sobre a auditoria fiscal do trabalho brasileira. Cadernos do Ceas, n. 239, p. 295-812, 2016.

SARMENTO. T. F. Cargos em extinção: as marcas das mudanças do e no trabalho. 2016. 150 f. Dissertação (Mestrado em Psicologia Social e Institucional) - Universidade Federal do Rio Grande do Sul, Porto Alegre, 2016.

SELIGMANN-SILVA, E. Trabalho e desgaste mental: o direito de ser dono de si mesmo. São Paulo: Cortez, 2011.

SPILKI, A.; TITTONI, J. O modo-indivíduo no serviço público: descartando ou descartável? Psicologia e Sociedade, v. 17, n. 3, p. $67-73,2005$.

Recebido em 02-01-2017

Aprovado em 21-08-2017. 